\title{
Mikania Micrantha Wilt Virus Alters Insect Vector's Host Preference to Enhance Its Own Spread
}

\author{
Rui-Long Wang ${ }^{1}$, Keyan Zhu-Salzman ${ }^{2}$, Mohammed Esmail Abdalla Elzaki ${ }^{3}$, \\ Qiao-Qiao Huang ${ }^{4}$, Shi Chen ${ }^{5}$, Zhi-Hui Ma ${ }^{1}$, Shi-Wei Liu ${ }^{1}$ and Jia-En Zhang ${ }^{1, *}$ \\ 1 Key Laboratory of Agro-Environment in the Tropics, Ministry of Agriculture, College of Natural Resources \\ and Environment, South China Agricultural University, Guangzhou 510642, China; \\ rlw2009@scau.edu.cn (R.-L.W.); 13924082629@163.com (Z.-H.M.); 13711379414@163.com (S.-W.L.) \\ 2 Departments of Entomology, Texas A\&M University, College Station, TX 77843, USA; ksalzman@tamu.edu \\ 3 College of Crop Science, Fujian Agriculture and Forestry University, Fuzhou 350000, China; \\ alzaki_mohammed@yahoo.com \\ 4 Environment and Plant Protection Institute, Chinese Academy of Tropical Agricultural Sciences, \\ Haikou 571101, China; cosplete@126.com \\ 5 College of Materials and Energy, South China Agricultural University, Guangzhou 510642, China; \\ chenshi@scau.edu.cn \\ * Correspondence: jeanzh@scau.edu.cn; Tel.: +86-20-85280211
}

Received: 4 March 2019; Accepted: 8 April 2019; Published: 9 April 2019

\begin{abstract}
As an invasive weed, Mikania micrantha Kunth has caused serious damage to natural forest ecosystems in South China in recent years. Mikania micrantha wilt virus (MMWV), an isolate of the Gentian mosaic virus (GeMV), is transmitted by Myzus persicae (Sulzer) in a non-persistent manner and can effectively inhibit the growth of $M$. micrantha. To explore the MMWV-M. micrantha-M. persicae interaction and its impact on the invasion of M. micrantha, volatile compounds (VOCs) emitted from healthy, mock-inoculated, and MMWV-infected plants were collected, and effects on host preference of the apterous and alate aphids were assessed with Y-shaped olfactometers. Gas chromatography-mass spectrometry (GC-MS) analysis indicated that MMWV infection changed the VOC profiles, rendering plants more attractive to aphids. Clip-cages were used to document the population growth rate of M. persicae fed on healthy, mock-inoculated, or MMWV-infected plants. Compared to those reared on healthy plants, the population growth of M. persicae drastically decreased on the MMWV-infected plants. Plant host choice tests based on visual and contact cues were also conducted using alate M. persicae. Interestingly, the initial attractiveness of MMWV-infected plants diminished, and more alate M. persicae moved to healthy plants. Taken together, MMWV appeared to be able to manipulate its plant host to first attract insect vectors to infected plants but then repel viruliferous vectors to promote its own dispersal. Its potential application for invasive weed management is discussed.
\end{abstract}

Keywords: Mikania micrantha wilt virus; Myzus persicae; virus-induced plant volatile; virus-host plant-insect vector interactions; odor cues; Gentian mosaic virus; Fabavirus

\section{Introduction}

Mikania micrantha Kunth (Asteraceae), commonly known as mile-a-minute weed, is a perennial vine. Although native to Central and South America, it has now become an important invasive weed in the Southeast Asia and Pacific regions [1]. Among the 10 worst weeds in the world, M. micrantha is a serious threat to the functioning local ecosystems and global biodiversity [1-4]. Due to its rapid growth, wide ecophysiological tolerance, strong reproduction, high phenotypic plasticity, and allelopathic inhibitory effect on neighboring plants [1,5], M. micrantha invasion in Southern China has caused substantial damage to natural ecosystems $[1,2,5]$. To limit the invasive weed, mechanical removal, 
chemical, biological, and ecological controls have been implemented over the past few years [3]. However, no single method can effectively reduce the losses caused by M. micrantha [1-3].

The majority of plant-infecting viruses are transmitted to their host plants by vectors [6]. Modes of insect-transmitted plant viruses are categorized into four types: (a) Non-persistently transmitted, stylet-borne; (b) semi-persistently transmitted, foregut-borne; (c) persistently transmitted, circulative; and (d) persistently transmitted, propagative [7]. Non-persistently transmitted (e.g., Cucumber mosaic virus (CMV)) and semi-persistently transmitted (e.g., Tomato chlorosis virus (ToCV)) viruses do not breach the gut barrier in their vectors; rather they are retained in the insect stylet or foregut prior to transmission [8]. Such viruses can be transmitted within seconds to hours after acquisition [8]. Persistent transmission, however, requires days to weeks [6,7]. Persistently transmitted circulative viruses (e.g., Potato leafroll virus (PLRV)) are able to cross the gut barriers and circulate in the insect hemolymph, but do not replicate in the insect vector. Persistently transmitted propagative viruses (e.g., Southern rice black streaked dwarf virus (SRBSDV) circulate and replicate in the insect vector [8]. Non-persistently transmitted viruses are acquired via short epidermal probes, which occur on the host and non-host plants of the vector during host selection, whereas persistently-transmitted viruses require phloem ingestion to be transmitted, which needs a specific vector of a suitable host-plant [6-8].

It is known that insect-transmitted plant viruses have developed different strategies to manipulate host-vector interactions and that the transmission mechanism greatly influences the strategies [9]. Persistently transmitted viruses tend to improve the host quality and promote long-term feeding, leading to higher reproductive rate, crowding, accelerated use of host resources, and eventual dispersal of viruliferous vectors [9-11]. Non-persistently transmitted viruses, on the other hand, often reduce plant quality, which inevitably increases vector restlessness and opportunities for virus acquisition and promotes rapid dispersal [9-11]. Infection of Camelina sativa by Turnip yellows virus (TuYV, circulative-persistent, non-propagative) enhanced palatability for Myzus persicae (Sulzer) [12]. The intrinsic growth rate of $M$. persicae was significantly higher and the pre-reproductive period was significantly shorter on plants infected by TuYV compared to uninfected plants [12]. Similarly, the pre-reproductive period of Bemisia tabaci females fed on tobacco plants infected with Tomato yellow leaf curl China virus (TYLCCNV, transmitted in a circular, persistent manner) was drastically improved, being 7-fold higher in longevity and 18-fold higher in fecundity than those on non-infected plants [13]. Aphis gossypii (Glover) and M. persicae grew more slowly on CMV-infected cucumber plants than those on uninfected plants indicative of reduced host quality [14].

Plant viruses, regardless of their mode of transmission, influence host-derived cues which tend to enhance vector attraction to infected hosts [9]. For example, A. gossypii and M. persicae preferred CMV-infected cucumber plants to healthy and mocked-inoculated plants [14]. More aphids were found to be attracted to tobacco plants infected with the Tobacco etch virus (TEV, transmitted in a non-persistent manner) than to healthy plants in a field evaluation experiment [15]. Virus-infected plants emit volatiles to makes them more attractive to insect vectors, which obviously would promote virus acquisition. However, after virus acquisition, the relative preference of the vector may shift to uninfected plants [14,16-18]. M. persicae reared on healthy Physalis floridana Rydb plants preferred to settle on potato plants infected by PLRV, whereas viruliferous $M$. persicae reared on PLRV-infected $P$. floridana plants preferred to settle on mock-inoculated potato plants [19]. Similarly, non-viruliferous Rhopalosiphum padi (L.) aphids preferred wheat infected by Barley yellow dwarf virus (BYDV), but once the aphids have acquired this virus, their settling preferences change, favoring healthy plants [16]. This subsequent host preference changes most likely would facilitate virus transmission and spreading after the vectors become viruliferous [14,16-18,20].

Mikania micrantha wilt virus (MMWV), an isolate of Gentian mosaic virus (GeMV) in the genus Fabavirus of the Secoviridae family, was initially found in 2008 in Guangdong Province, China. $M$. persicae can efficiently transmit this virus in a non-persistent manner [2,4,21]. MMWV-infected $M$. micrantha displays wilt, leaf crimpling and malformation symptoms [2]. Because of the inhibitory 
effects on host plant growth and reproduction, MMWV has been proposed to be used as a control agent for M. micrantha [2,4].

Our previous field observations and laboratory experiments found that more M. persicae initially settles on MMWV-infected M. micrantha leaves [2,4]. To investigate whether MMWV-M. micrantha-M. persicae interaction enhances transmission of $\mathrm{MMWV}$, we analyzed the plant volatile organic compounds (VOCs) emission before and after MMWV infection. We documented M. persicae orientation preference in response to volatile cues originating from healthy, mock-inoculated or MMWV-infected-plants. Aphid population growth was also measured on healthy, mock-inoculated, and MMWV-infected plants. In addition, the initial and after-host-contact distributions of alate M. persicae were analyzed on healthy, mock-inoculated, and MMWV-infected plants.

\section{Materials and Methods}

\subsection{Insects}

The M. persicae colony was originated from field-grown rapeseed (Capsicum annuum L.) at Research Farm Field, South China Agriculture University, Guangzhou (N 23 $16^{\prime}$, E 113 $\left.34^{\prime}\right)$ and maintained on soybean (Glycine $\max$ (L.) Merr.) in an insectary $\left(25 \pm 2{ }^{\circ} \mathrm{C}, 70 \pm 5 \%\right.$ relative humidity and a $14 \mathrm{~h}$ light: $10 \mathrm{~h}$ dark photoperiod) for more than eight months.

\subsection{Plants}

M. micrantha plants at vegetative stage approximately $150 \mathrm{~cm}$ tall were collected in May 2017 from the same Research Farm Field as described above. They were cut into $10 \mathrm{~cm}$ long pieces and planted in plastic pots $(8.5 \mathrm{~cm}$ diameter; $7 \mathrm{~cm}$ height $)$ in a greenhouse $\left(25 \pm 1{ }^{\circ} \mathrm{C}, 75 \pm 5 \%\right.$ relative humidity, $14 \mathrm{~h}$ light: $10 \mathrm{~h}$ dark photoperiod). Plants were allowed to climb on $70 \mathrm{~cm}$ bamboo sticks and watered with diluted Hoagland solution $(25 \% v / v)$ twice a week.

\subsection{MMWV Inoculation Procedures}

MMWV, also obtained from the same location in May 2016, was maintained on M. micrantha in a glasshouse at South China Agriculture University, Guangzhou. Young, highly symptomatic leaves of MMWV-infected M. micrantha were ground in $0.5 \mathrm{M}$ potassium phosphate buffer ( $\mathrm{pH} 7.5$ ). Plants used for infection were mechanically inoculated with MMWV. To inoculate, the fourth and fifth leaves (counted basipetally from the apex) of the plants (about $45 \mathrm{~cm}$ tall) were dusted with carborundum powder and inocula were spread over the leaves using a cotton-tipped applicator [14]. Mock-inoculated plants were generated by applying inoculation buffer to the leaves at the same positions.

\subsection{Choice Tests}

For choice tests based on olfactory cues, a Y-shaped tube $(2 \mathrm{~cm}$ inner diameter) consisting of a central tube ( $13 \mathrm{~cm}$ long) and two arms $\left(10 \mathrm{~cm}\right.$ long, offset by $\left.60^{\circ}\right)$ was connected to $36 \mathrm{~L}$ glass desiccators. Five healthy, mock-inoculated, or MMWV-infected plants (10 days after inoculation) were placed in glass desiccators, respectively. The GC-grade air was pumped into the glass desiccators

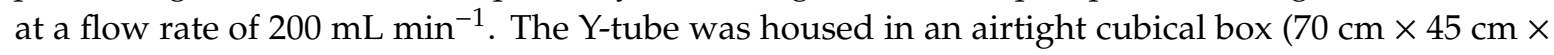
$30 \mathrm{~cm}$ ) with a $25 \mathrm{~W}$ filament lamp giving a constant light $25 \mathrm{~cm}$ above each arm. The temperature in the glass desiccators was $25^{\circ} \mathrm{C}$ and the relative humidity was $70 \%$. An M. persicae aphid (starved for $1 \mathrm{~h}$ before tests) was individually placed in the central tube and allowed to choose between the two arms. A choice was registered if $M$. persicae passed the threshold line located $3 \mathrm{~cm}$ away from the Y-junction. A "no choice" was marked if it failed to decide during the $5 \mathrm{~min}$ testing period [22]. Pairings for host preference tests were designed as follows: (i) Healthy vs. MMWV-infected, (ii) healthy vs mock-inoculated, and (iii) mock-inoculated vs. MMWV-infected. Thirty M. persicae were tested for each pairing. When 5 M. persicae individuals had been tested, the odor sources were interchanged. The 
Y-tube and plants were replaced after testing of 10 aphids. All Y-tubes were cleaned with $95 \%$ alcohol and dried in a $120^{\circ} \mathrm{C}$ oven before use [20,22]. A total of 150 aphids in 5 replicates

Choice tests based on visual and contact cues followed the procedure of previous studies with minor modifications $[14,16,23]$. A glass Petri dish $(12 \mathrm{~cm}$ diameter) lined with a filter paper was divided into two parts by pencil marks. Two leaves, each still attached to a differently treated plant, (i) healthy vs. MMWV-infected, (ii) healthy vs mock-inoculated, and (iii) mock-inoculated vs. MMWV-infected, were placed in the Petri dish, into which 50 alate M. persicae were released. Petri dishes were sealed with Parafilm perforated to allow air movement. The number of aphids settled on each leaf was counted $30 \mathrm{~min}$ and $60 \mathrm{~min}$ later, respectively. A total of 750 aphids in 15 replicates were tested for each dual-choice bioassay.

\subsection{Collection of Plant Volatiles}

Ten healthy, mock-inoculated or MMWV-infected plants (10 days after inoculation) were placed in a glass desiccator $(36 \mathrm{~L})$. Plants were illuminated with fluorescent bulbs $\left(50 \mu \mathrm{mol} \mathrm{m}{ }^{-2} \mathrm{~s}^{-1}\right.$ with a photoperiod of $16 \mathrm{~h}$ light: $8 \mathrm{~h}$ dark). The temperature in the glass desiccators was $25^{\circ} \mathrm{C}$, and the relative humidity was $70 \%$. The Pots with potting soil were wrapped with aluminum foil to prevent water evaporation and volatile emission from the soil. A watered pot wrapped in aluminum foil without plants was used as a negative control. The glass desiccator was connected to a GC-grade air generator (QL-3, Shandong Saikesaisi Hydrogen Energy Co., Ltd., Shandong, China) through a cork plug with two openings allowing gases to go in and out at a flow rate of $350 \mathrm{ml} \mathrm{min}$. $^{-1}$. A clean Pasteur glass pipette was inserted in the outlet of the cock plug and VOCs were collected with divinyl-benzene/carboxen/polydimethylsiloxane (DVB/CAR/PDMS, $50 \mu \mathrm{m} / 30 \mu \mathrm{m}$, No.57348-U) solid-phase microextraction (SPME) fibers (Bellefonte, PA, USA). The manual SPME holder was purchased from Supelco (Bellefonte, PA, USA) (Figure 1). SPME fibers were conditioned at $250{ }^{\circ} \mathrm{C}$ for $1 \mathrm{~h}$, and then placed in the Pasteur glass pipette to absorb VOCs for $2 \mathrm{~h}$. All assays were performed in triplicate.

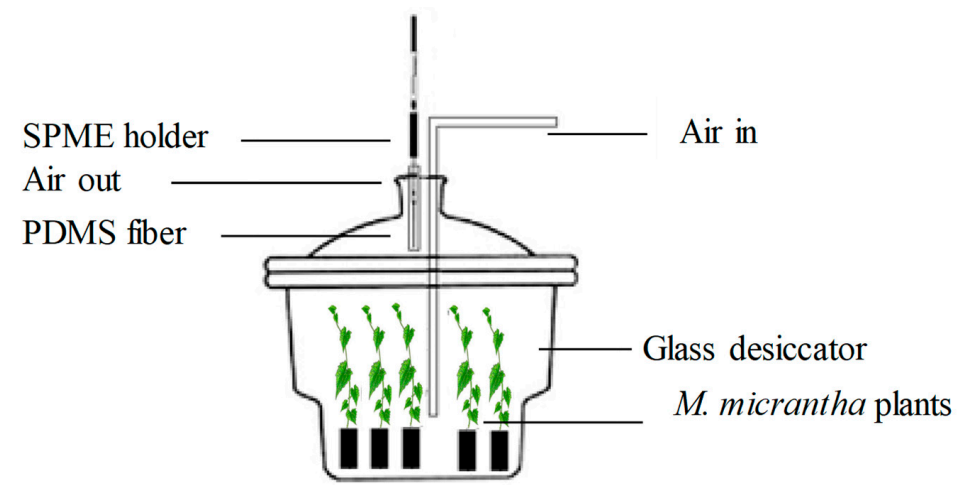

Figure 1. The schematic device used for the SPME extraction of volatile compounds (VOCs) emitted by M. micrantha plants.

\subsection{Volatile Analysis}

The SPME fibers were removed and VOCs were analyzed using gas chromatography-mass spectrometry (GC-MS, TSQ Quantum XLS, Thermo Fisher Scientific Inc., USA) equipped with a TG-5HT column $\left(30 \mathrm{~m} \times 0.25 \mathrm{~mm} \times 0.25 \mu \mathrm{m}\right.$, Thermo Fisher Scientific Inc., USA), helium $\left(1 \mathrm{~mL} \mathrm{~min}{ }^{-1}\right.$ gas flow rate), a split injection temperature of $220^{\circ} \mathrm{C}$, a source temperature of $200{ }^{\circ} \mathrm{C}$, an ionization potential of $70 \mathrm{eV}$, and a scan range of 35-450 amu. Samples were injected with an injection temperature of $220^{\circ} \mathrm{C}$, the oven temperature, starting at $60^{\circ} \mathrm{C}$ (kept for $\left.3 \mathrm{~min}\right)$, was increased $\left(10^{\circ} \mathrm{C} \mathrm{min}^{-1}\right)$ to $120^{\circ} \mathrm{C}$, then further increased to reach $180^{\circ} \mathrm{C}\left(5^{\circ} \mathrm{C} \mathrm{min}^{-1}\right)$ and finally to $250{ }^{\circ} \mathrm{C}\left(25^{\circ} \mathrm{C} \mathrm{min}^{-1}\right.$, and was kept for $3 \mathrm{~min}$ ). Individual compound peaks were identified by reference library search using authentic standards and the National Institute of Standards and Technology MS database (NIST MS 
Search 2.0). Compounds were quantified on the basis of individual peak areas and the quantitative analysis of each volatile compound (expressed as a percentage of area) was determined by the peak area normalization method.

\subsection{Population Growth of M. persicae}

Five M. persicae apterous adults were placed in a clip cage $(4 \mathrm{~cm}$ diameter $\times 3.5 \mathrm{~cm}$ height $)$ with soft nylon mesh (size 80 mesh) covering one side to allow ventilation. The cage was clipped to a leaf of a plant (healthy, mock-inoculated or MMWV-infected) supported by a bamboo stick. All aphids except three neonate nymphs (foundresses) were removed $12 \mathrm{~h}$ later. The foundresses were checked daily and the total numbers of aphids produced was recorded after 10 days. The population growth rate was calculated as the increase in the number of aphids per colony per day per plant [24]. Fifty single-aphid replicates per treatment were included in the study.

\subsection{Data Analysis}

All statistical analyses were performed using SPSS 20.0 software (IBM, SPSS, Chicago, IL, USA). The distribution of alate M. persicae based on visual and contact cues of healthy, mock-inoculated, or MMWV-infected plants at $30 \mathrm{~min}$ and $60 \mathrm{~min}$ time points was analyzed using the generalized linear model. The population growth of M. persicae was analyzed by one-way ANOVA followed by Duncan's multiple range test. Statistical differences were considered significant at $p<0.05$. Principal Component Analysis (PCA) was used to analyze the relative peak area of each compound of the VOCs collected from healthy, mock-inoculated, or MMWV-infected plants.

\section{Results}

\subsection{Odor from MMWV-Infected Plants is More Attractive to Aphids}

To determine the potential of volatiles in host preference of M. persicae, healthy, mock-inoculated, or MMWV-infected plants were evaluated in choice tests using a Y-tube olfactometer. Apterous $M$. persicae preferred the infected (59.3\%) over healthy plants (30.7\%) $(t=5.963, d f=8, p<0.001)$ (Figure 2), although $10 \%$ did not make their choice. Likewise, the majority of aphids preferred the infected plants $(62.7 \%)$ to the mock-inoculated plants $(25.3 \%)(t=5.671, d f=8, p<0.001)$. No significant difference was found when choice was made between healthy and mock-inoculated plants $(t=0.346, d f=8$, $p=0.738)$. 


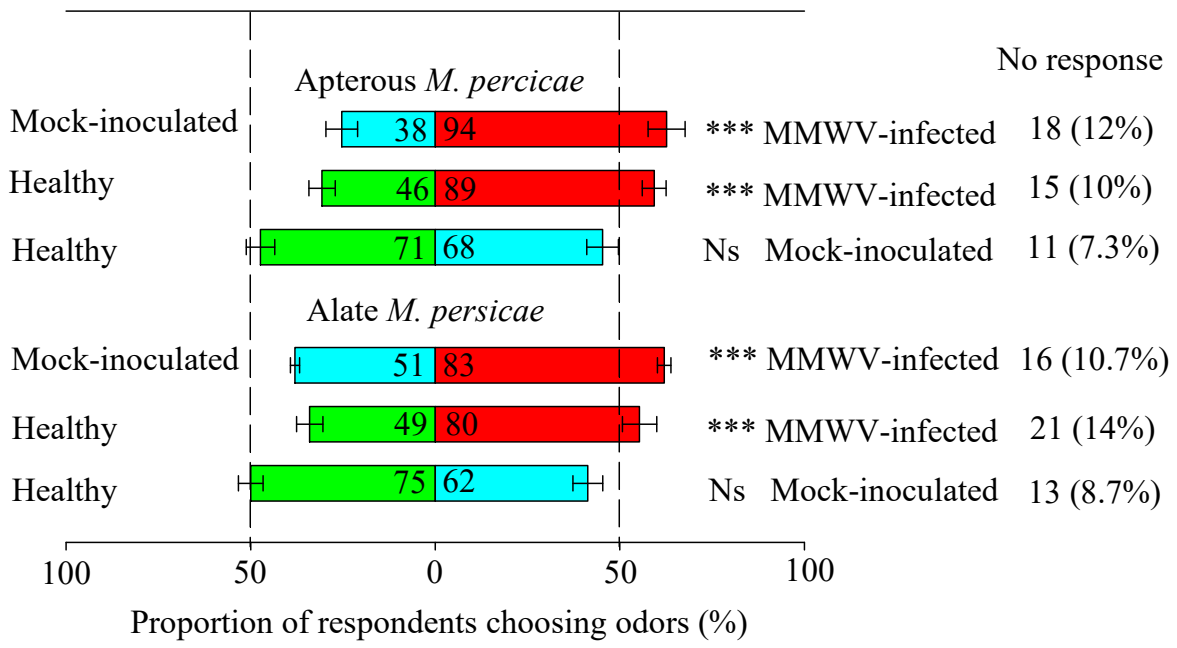

Figure 2. The response of Myzus persicae to different odor stimuli. For each pair of stimuli, a total $150 \mathrm{M}$. persicae were tested by the Y-shaped olfactometer. Data were presented as the mean \pm SE. Bars denoted by asterisk indicate a significant preference for the treatment $\left({ }^{*} p<0.05,{ }^{* *} p<0.01,{ }^{* * *} p<0.001\right)$. Ns: No significant difference $(p>0.05)$. Healthy plants are shown in green; MMWV-infected plants are shown in red; Mock-inoculated plants are shown in blue. Numbers of individuals that responded or did not respond are given.

Similar observations were obtained with alate $M$. persicae: $53.3 \%$ aphids preferred the infected plants which were significantly more than that on healthy plants $(32.7 \%)(t=9.347, d f=8, p<0.001)$. When facing a choice between mock-inoculated and MMWV-infected plants, $34.0 \%$ aphids selected the former and 55.3\% preferred the latter $(t=3.635, d f=8, p<0.001)$. No significant difference in aphid numbers was found between healthy and mock-inoculated plants $(t=1.658, d f=8, p=0.136)$. These results indicated that odor from MMWV-infected plants was significantly more attractive to $M$. persicae than that of the healthy or mock-inoculated plants.

\subsection{Aphid Distribution in Preference for Contact Cues}

We also assessed the host preference of alate $M$. persicae based on visual and contact cues from plant leaves (Figure 3). At $30 \mathrm{~min}$ after release, $46.3 \%$ aphids $M$. persicae $(d f=1, F=4.697, p<0.05$ ) were found on MMWV-infected plants and 39.1\% on healthy plants (Figure 3A). Also, 14.6\% of M. persicae made no choice. Similarly, $48.1 \%$ were found on infected plants relative to $42.7 \%$ on mock-inoculated plants $(d f=1, F=6.122, p<0.05$ ) (Figure 3B). However, at the $60 \mathrm{~min}$ time point, for the infected vs. healthy plant pair, aphids on the MMWV-infected plants dropped to $26.7 \%(d f=1$, $F=35.317, p<0.001)$ compared to an increase to $61.2 \%$ on the healthy plants $(d f=1, F=45.493, p<$ 0.001) (Figure 3A). Likewise, on the infected vs. mock-inoculated plant pair, more aphids preferred mock-inoculated $(50.1 \%)$ to MMWV-infected plants $(40.9 \%)(d f=1, F=10.038, p<0.05)$ after $60 \mathrm{~min}$ (Figure 3B). In contrast, no significant difference was found between aphid numbers when choices were made between healthy and mock-inoculated plants at both $30 \min (d f=1, F=3.824 p=0.061)$ and $60 \min (d f=1, F=2.523, p=0.123$ ) time points (Figure 3C). These results indicated that, although MMWV-infected plants were more attractive initially, more M. persicae emigrated to healthy plants once they probed or fed on infected plants. 

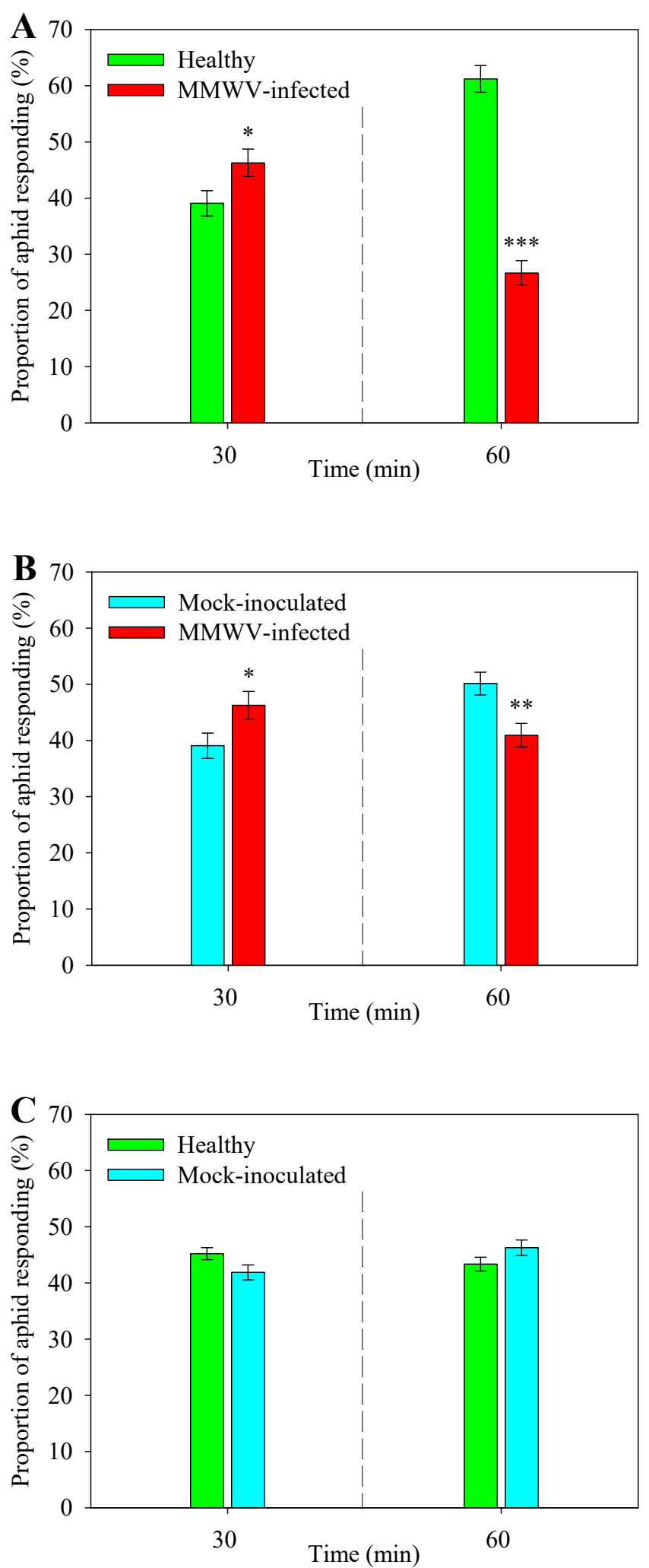

Figure 3. Distribution of alate Myzus persicae in response to contact cues of healthy, mock-inoculated and MMWV-infected plants after $30 \mathrm{~min}$ and $60 \mathrm{~min}$. (A) Healthy vs. MMWV-infected plants, (B) Mock-inoculated vs. MMWV-infected plants, (C) Healthy vs. mock-inoculated plants. Each replicate (n $=15$ ) consisted of fifty alate M. persicae. Asterisks indicate significant differences ${ }^{*} p<0.05,{ }^{* *} p<0.01$, *** $p<0.001)$. 


\subsection{Chemical Analysis of Volatiles}

The volatiles from healthy, mock-inoculated, and MMWV-infested plants (10 days after inoculation) were analyzed by GC-MS (Figure 4). In total, 31 compounds were identified, of which, $\beta$-cubebene $(12.0 \%)$, germacrene $\mathrm{D}(9.7 \%), \beta$-himachalene $(8.9 \%), \alpha$-zingiberene $(6.9 \%)$, and $\beta$-caryophyllene $(6.3 \%)$ were the main VOCs released from the healthy plants (Figure 4). In contrast, $\alpha$-curcumene $(12.6 \%)$, $\beta$-cubebene (12.3\%), $\alpha$-zingiberene (8.9\%), and $\beta$-caryophyllene $(6.1 \%)$ were the main compounds from MMWV-infected plants (Figure 4). Compared to the healthy plants, MMWV-infected plants significantly increased their emission of $\alpha$-curcumene $(94.1 \%)$, humulene $(88.7 \%)$, and $\alpha$-ocimene (86.7\%), but decreased the emission of $\beta$-himachalene (586.4\%), $\beta$-sesquiphellandrene (371.7\%), and ç-muurolene (321.7\%), respectively (Figure 4). Interestingly, isocaryophillene (13.5\%), isoledene $(11.6 \%)$, and $\beta$-caryophyllene (9.4\%), trans- $\alpha$-bergamotene $(7.0 \%)$, and $\alpha$-muurolene $(6.0 \%)$ were found to be the major VOCs from mock-inoculated plants, distinct from those identified from healthy plants (Figure 4). On the other hand, no VOCs were detected from the negative control (pot wrapped in aluminum foil without plants). Perhaps plant handling, i.e., applying buffer to plants, could have introduced slight damage to the plants which was sufficient to cause changes in VOCs production. Such discrepancy has also been reported by other researchers [14,25]. GC-MS analysis revealed a significant increase in quantities of volatiles released by MMWV-infected plants relative to the healthy and mock-inoculated plants, but no qualitative differences were detected (Figure 4). The PCA analysis separated healthy, mock-inoculated, and MMWV-infected plants from each other (Figure 5, PC1 $=46.84 \%$, PC2 $=32.79 \%$ ). Therefore, MMWV-infection and plant handling significantly changed the VOCs profile of M. micrantha.

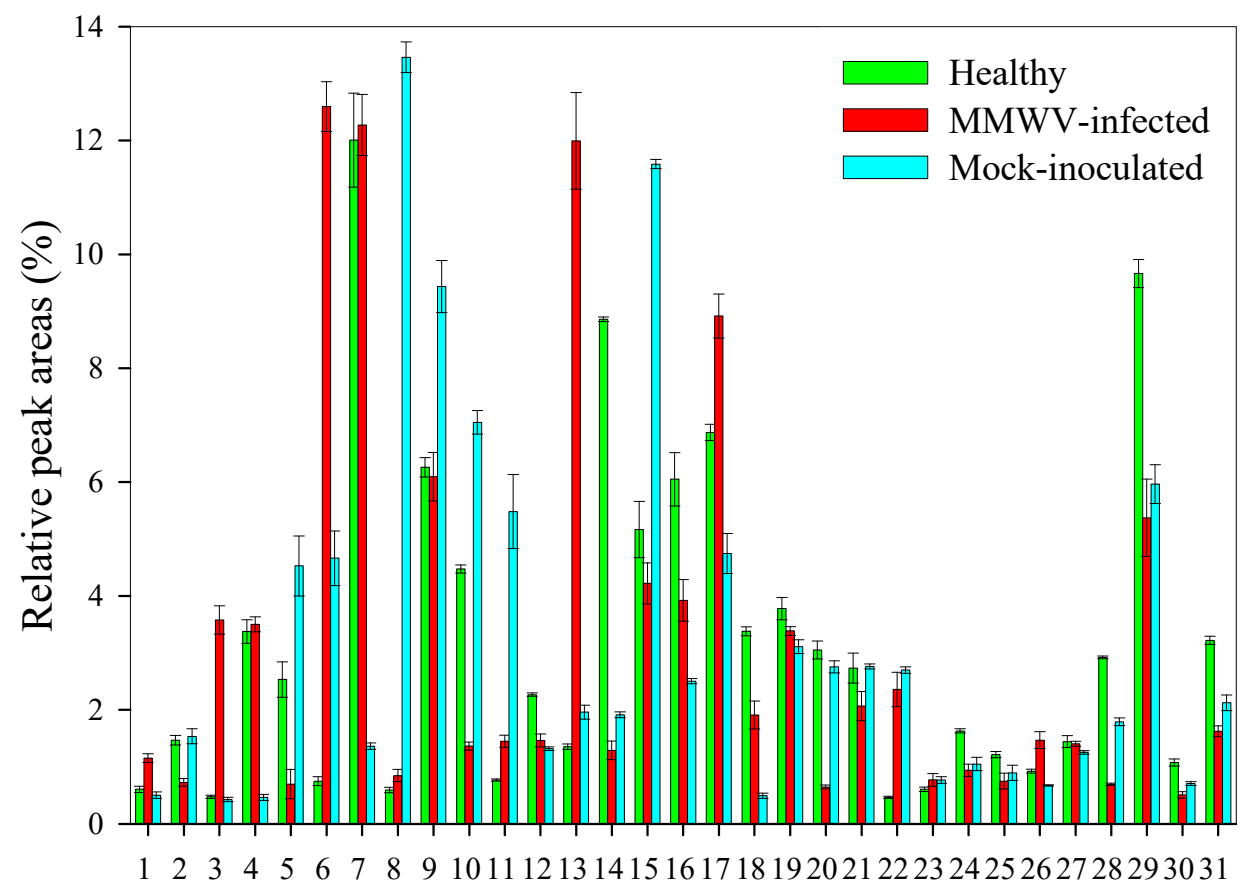

Figure 4. VOCs released from healthy, Mikania micrantha wilt virus (MMWV)-infected, or mock-inoculated plants. Quantitative analyses of each volatiles organic compound (expressed as area percentage) were carried out by a peak area normalization measurement. Values are mean $\pm \mathrm{SE}$ (three replicates). 1, Hexanal; 2, 2-Hexenal; 3, $\alpha$-Ocimene; 4, $\alpha$-Cubebene; $5, \alpha$-Copaene; $6, \alpha$-Curcumene; 7, $\beta$-Cubebene; 8 , Isocaryophillene; 9, $\beta$-Caryophyllene; 10 , trans- $\alpha$-Bergamotene; 11 , Cedrene; 12 , cis- $\beta$-Farnesene; 13 , Humulene; 14 , $\beta$-Himachalene; 15 , Isoledene; $16,(+)$-Epi-bicyclosesquiphellandrene; 17, $\alpha$-Zingiberene; 18, $\alpha$-Muurolene; 19, $\beta$-Bisabolene; 20, $\beta$-Sesquiphellandrene; 21, $\delta$-Cadinene; 22 , $\beta$-Vatirenene; 23, $\alpha$-Guaiene; 24, Cyclohexene; 25, Isolongifolene; 26, (E)-Nerolidol; 27, ç-Himachalene; 28, ç-Muurolene; 29, Germacrene D; 30, trans-Sesquisabinene hydrate; 31, 8-oxo-9H-Cycloisolongifolen. 


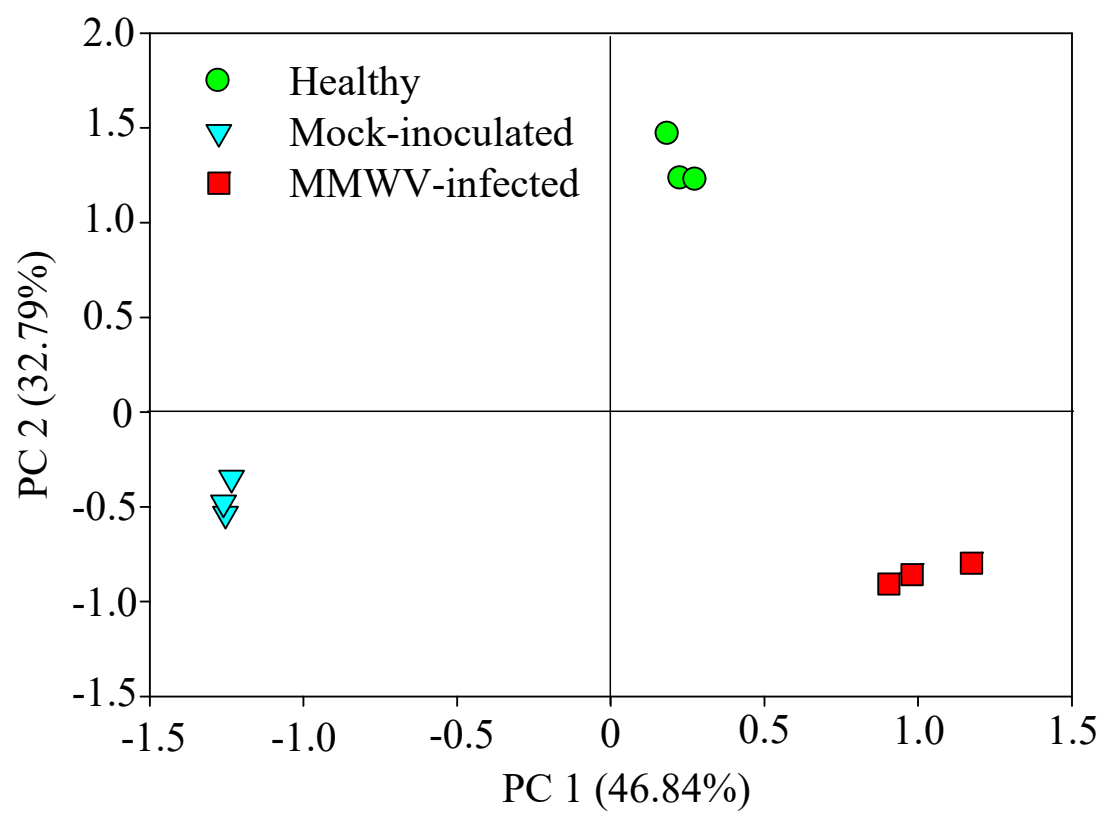

Figure 5. Principal component analysis (PCA) of VOCs released from healthy, MMWV-infected and mock-inoculated plants.

\subsection{Effect of MMWV Infection on the Development of the M. persicae Population}

We also examined the effect of host plants on aphid population growth and reproduction using clip-cages. (Figure 6). The average aphid growth rate on MMWV-infected plants was 3.90 aphids per day per plant, which was significantly lower than that on healthy (6.73 aphids per day per plant) and mock-inoculated plants (7.01 aphids per day per plant) (Figure 6). The $72.8 \%$ decrease indicated that MMWV-infested plants were not a suitable host for aphids compared to healthy plants.

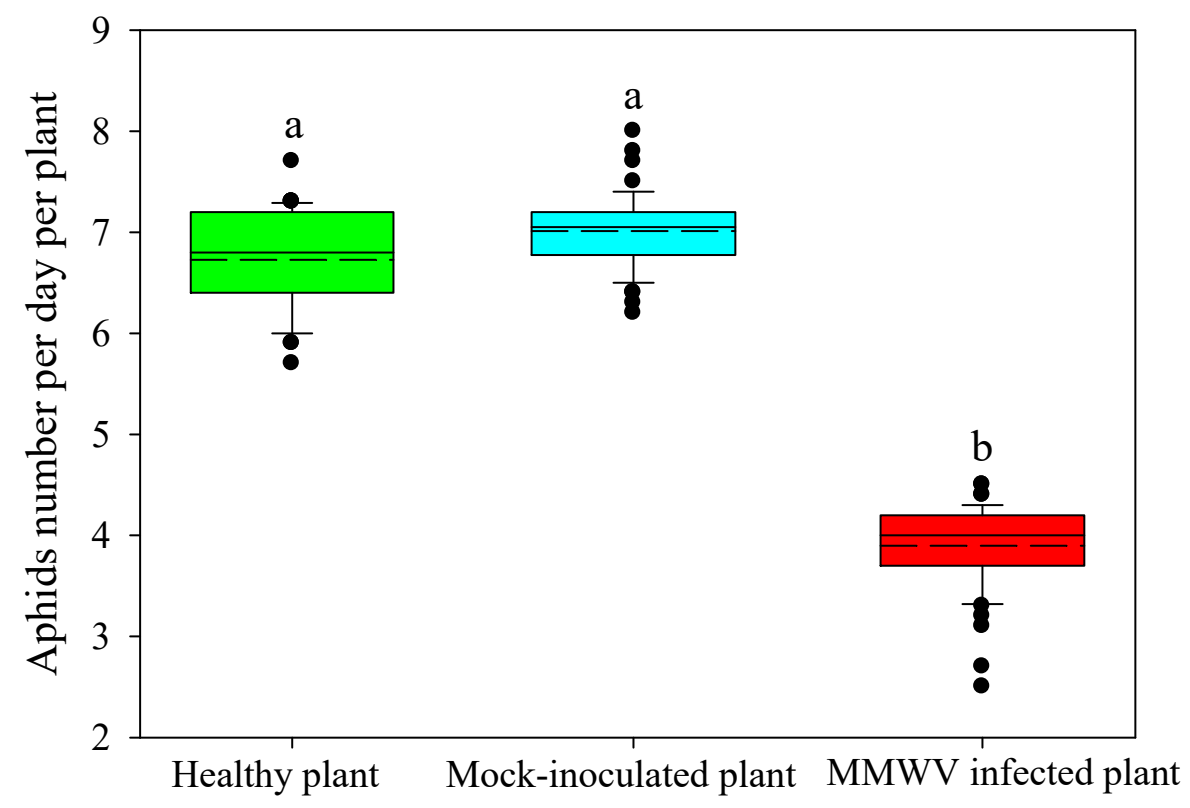

Figure 6. Effect of healthy plants $(n=50)$, mock-inoculated plants $(n=50)$, and MMWV-infected plants $(\mathrm{n}=50)$ on the population growth rate of Myzus persicae. Box plot description: The long dashed line is the mean, the solid line is the median, the borders of the box are the first and third quartiles, the whiskers (error bars) represent 1.5 times the interquartile range, and points beyond the end of the whiskers are outliers. Different letters above bars indicate significant differences $(p<0.05)$ according to Duncan's multiple range test. 


\section{Discussion}

Plant viruses affect host plants in different ways to mediate vector attraction to, arrestment on, and dispersal from infected plants [9,16,19,25-27]. For example, aphids are attracted to plants infected with the non-persistent CMV and quickly left the plant after landing and avoided prolonged feeding. Such behavior presumably would enhance virus transmission particularly effectively with non-persistent viruses [14,25]. Persistently-transmitted viruses often promote long-term feeding as shown in Sitobion avenae, which is engaged in faster phloem-finding behavior and longer feeding time on plants infected with BYDV or PLRV than on non-infected plants $[25,28]$. A similar phenomenon has been observed with R. padi. Initially, non-infected R. padi significantly preferred wheat plants infected with BYDV compared to mock-inoculated plants, but ultimately viruliferous $R$. padi significantly preferred mock-inoculated wheat to virus-infected plants [16], which also would promote the spread of this persistently transmitted virus. In our MMWV-M. micrantha-M. persicae system, a change of plant host preference was also observed, supporting the "Host Manipulation Hypothesis" [14]. Gustatory, olfactory, and visual cues may have contributed to this preference switch and promotion of MMWV transmission.

Modified VOCs emissions due to virus infection can potentially serve as important mediators in decision making by insect vectors when selecting a host plant $[25,29]$. CMV-infected C. pepo in the field released significantly greater quantities of volatiles than healthy plants [14], presumably being responsible for attracting aphids to CMV-infected plants [14]. The total concentration of headspace VOCs differed between PLRV-infected and mock-inoculated potato plants as well. The concentration of monoterpenes, green leaf volatiles, and sesquiterpenes from PLRV-infected potato plants were higher than those of mock-inoculated plants [19]. Mock-inoculated tomato plants emitted significantly higher amounts of the terpenes $\alpha$-pinene, 4-carene, $\alpha$-phellandrene, terpinene, and $\beta$-phellandrene than Tomato severe rugose virus (ToSRV)-infected plants, indicating that ToSRV infection suppresses some volatile terpenes [25]. Pea plants inoculated with persistently transmitted viruses (e.g., Bean leaf roll virus (BLRV) or Pea enation mosaic virus (PEMV)) had significantly higher concentrations of green leaf volatiles relative to concentrations of monoterpenes, compared to either sham-inoculated or control plants [30]. In our study, M. persicae apparently could discriminate between healthy, MMWV-infected, or mock-inoculated plants possibly based on characteristics of the VOCs blends.

Virus-host plant-insect vector interactions could affect population growth of the insect vectors which would further influence virus transmission [16,31-33]. While some studies indicate that virus-infected plants are superior hosts for aphid reproduction [31,34,35], others show the opposite outcome [14,34]. In most cases, non-persistently transmitted viruses have negative effects on vector survival, fecundity or longevity, while persistently and semi-persistently transmitted viruses positively impact on one or more of these parameters [9]. For example, TYLCV mediated alterations to plant nutritional traits and defensive responses improve the growth and reproduction of $B$. tabaci Mediterranean (MED) [31]. MED feeding on TYLCV-infected plants gained $68 \%$ more weight and laid $81 \%$ more eggs than those feeding on mock-inoculated tomato plants. MED can both rapidly acquire and effectively transmit the persistently transmitted TYCLV. The beneficial effects of TYLCV infection on MED fitness should in turn favor TYLCV transmission [31]. Compared with non-infected sweet potato (Ipomoea batatas) plants, M. persicae displayed greater reproduction on the plants which were coinfected with the non-persistent transmitted viruses (Sweet potato feathery mottle virus (SPFMV), Sweet potato virus $G$, and Sweet potato virus 2) [34]. On the other hand, populations of A. gossypii and $M$. persicae were significantly reduced on the CMV-infected cucumber plants compared to those on healthy or mock-inoculated plants [14]. Also, compared to aphids on non-infected Ipomoea hederacea plants, the intrinsic rate of increase of $M$. persicae was significantly lower on SPFMV-infected plants, possibly due to an altered quality of infected plants [34]. In our study, the reduced population growth rate of $M$. persicae reared on the MMWV-infected plants indicates that MMWV-infected M. micrantha plants were also less suitable hosts. Under such a scenario, the negative effect of virus-infected plants 
may prompt vectors to depart and search for healthy, better-suited plants after landing and probing virus-infected plants. Dispersal of vectors would lead to the enhanced spread of MMWV.

Invasions of exotic species have become one of the major threats to ecosystem functioning and global biodiversity [35]. Some viruses have been suggested to be used to control of the invasive species [4,36-43]. For example, Solenopsis invicta virus 3 (SINV-3), Tobacco mild green mosaic virus (TMGMV) have been suggested to as a control agent for invasive species Solenopsis invicta $[38,40]$ and Impatiens glandulifera $[37,41]$, respectively. Although MMWV is not lethal for M. micrantha, it is the only virus that has been found to inhibit the growth and reproduction of $M$. micrantha [2,4]. Of course, extensive studies are needed to understand its natural reservoirs, host range, persistence in natural conditions, and the potential effects on crops and other plant species before considering MMWV as a candidate biocontrol tool for M. micrantha. Such detailed investigation is particularly important for non-persistently-transmitted viruses (e.g., MMWV) that can be transmitted by a potential vector landing on non-host plants and then starting its host selection behavior.

Taken together, this study provides more insight into virus-host plant-insect vector interactions. Future research should focus on the biological, chemical, or physiological processes and molecular mechanisms underlying MMWV-M. micrantha-M. persicae interactions.

Author Contributions: Conceptualization, R.-L.W., K.Z.-S. and J.-E.Z.; Data curation, R.-L.W.; Formal analysis, R.-L.W., K.Z.-S., M.E.A.E., Q.-Q.H., S.C., Z.-H.M. and S.-W.L.; Funding acquisition, R.-L.W.; Methodology, R.-L.W., Z.-H.M. and S.-W.L.; Writing-original draft, R.-L.W., K.Z.-S., M.E.A.E. and J.-E.Z.; Writing-review \& editing, R.-L.W., K.Z.-S., M.E.A.E., Q.-Q.H., S.C., Z.-H.M., S.-W.L. and J.-E.Z.

Funding: This research was financially supported by the National Natural Science Foundation of China (No. 31470576) and the Natural Science Foundation of Guangdong Province, China (No. 2017A030313188).

Conflicts of Interest: The authors declare no conflict of interest exists.

\section{References}

1. Zhang, L.Y.; Ye, W.H.; Cao, H.L.; Feng, H.L. Mikania micrantha H.B.K. in China-An overview. Weed Res. 2004, 44, 42-49. [CrossRef]

2. Wang, R.L.; Ding, L.W.; Sun, Q.Y.; Li, J.; Xu, Z.F.; Peng, S.L. Genome sequence and characterization of a new virus infecting Mikania micrantha H.B.K. Arch. Virol. 2008, 153, 1765-1770. [CrossRef] [PubMed]

3. Shen, S.; Xu, G.; Clements, D.R.; Jin, G.; Chen, A.; Zhang, F.; Kato-Noguchi, H. Suppression of the invasive plant mile-a-minute (Mikania micrantha) by local crop sweet potato (Ipomoea batatas) by means of higher growth rate and competition for soil nutrients. BMC Ecol. 2015, 15, 1. [CrossRef] [PubMed]

4. Wang, G.; Yuan, K.; Zhang, S.; Wang, R. Influence of Mikania micrantha wilt virus on growth, reproduction and allelopathic potential of its host. Allelopath. J. 2015, 35, 87-96.

5. Huang, F.; Peng, S.; Chen, B.; Liao, H.; Huang, Q.; Lin, Z.; Liu, G. Rapid evolution of dispersal-related traits during range expansion of an invasive vine Mikania micrantha. Oikos 2015, 124, 1023-1030. [CrossRef]

6. Ng, J.C.K.; Falk, B.W. Virus-vector interactions mediating nonpersistent and semipersistent transmission of plant viruses. Annu. Rev. Phytopathol. 2006, 44, 183-212. [CrossRef]

7. Whitfield, A.E.; Falk, B.W.; Rotenberg, D. Insect vector-mediated transmission of plant viruses. Virology 2015, 479, 278-289. [CrossRef]

8. Cassone, B.J.; Wijeratne, S.; Michel, A.P.; Stewart, L.R.; Chen, Y.; Yan, P.; Redinbaugh, M.G. Virus-independent and common transcriptome responses of leafhopper vectors feeding on maize infected with semi-persistently and persistent propagatively transmitted viruses. BMC Genom. 2014, 15, 133. [CrossRef]

9. Mauck, K.; Bosque-Pérez, N.A.; Eigenbrode, S.D.; De Moraes, C.M.; Mescher, M.C. Transmission mechanisms shape pathogen effects on host-vector interactions: Evidence from plant viruses. Funct. Ecol. 2012, 26, 1162-1175. [CrossRef]

10. Mauck, K.E.; De Moraes, C.M.; Mescher, M.C. Effects of pathogens on sensory-mediated interactions between plants and insect vectors. Curr. Opin. Plant Biol. 2016, 32, 53-61. [CrossRef]

11. Mauck, K.E.; Chesnais, Q.; Shapiro, L.R. Evolutionary determinants of host and vector manipulation by plant viruses. In Advances in Virus Research, 1st ed.; Malmstrom, C.M., Ed.; Academic Press: Cambridge, MA, USA, 2018; Volume 101, pp. 189-250. 
12. Chesnais, Q.; Couty, A.; Uzest, M.; Brault, V.; Ameline, A. Plant infection by two different viruses induce contrasting changes of vectors fitness and behavior. Insect Sci. 2019, 26, 86-96. [CrossRef]

13. Jiu, M.; Zhou, X.P.; Tong, L.; Xu, J.; Yang, X.; Wan, F.H.; Liu, S.S. Vector-virus mutualism accelerates population increase of an invasive whitefly. PLoS ONE 2007, 2, e182. [CrossRef]

14. Mauck, K.E.; De Moraes, C.M.; Mescher, M.C. Deceptive chemical signals induced by a plant virus attract insect vectors to inferior hosts. Proc. Natl. Acad. Sci. USA 2010, 107, 3600-3605. [CrossRef]

15. Eckel, R.V.W.; Lampert, E.P. Relative attractiveness of tobacco etch virus-infected and healthy flue-cured tobacco plants to aphids. J. Econ. Entomol. 1996, 89, 1017-1027. [CrossRef]

16. Ingwell, L.L.; Eigenbrode, S.D.; Bosque-Pérez, N.A. Plant viruses alter insect behavior to enhance their spread. Sci. Rep. 2012, 2, 578. [CrossRef]

17. Dietzgen, R.G.; Mann, K.S.; Johnson, K.N. Plant virus-insect vector interactions: Current and potential future research directions. Viruses 2016, 8, 303. [CrossRef]

18. Eigenbrode, S.D.; Bosque-Pérez, N.A.; Davis, T.S. Insect-borne plant pathogens and their vectors: Ecology, evolution, and complex interactions. Ann. Rev. Entomol. 2017, 63, 169-191. [CrossRef]

19. Rajabaskar, D.; Bosque-Pérez, N.A.; Eigenbrode, S.D. Preference by a virus vector for infected plants is reversed after virus acquisition. Virus Res. 2014, 186, 32-37. [CrossRef]

20. Wang, H.; Xu, D.; Pu, L.; Zhou, G. Southern rice black-streaked dwarf virus alters insect vectors' host orientation preferences to enhance spread and increase rice ragged stunt virus co-infection. Phytopathology 2013, 104, 196-201. [CrossRef]

21. Wang, R.L.; Chen, Y.; Zhang, H.; Guan, A.M.; Wang, Z.Y.; Gong, X.; Yin, Y.; Zeng, R.S. Host range, transmitting vector, and damage characteristics of Mikania micrantha wilt virus. Chin. J. Ecol. 2013, 32, 72-77.

22. Wu, D.; Qi, T.; Li, W.X.; Tian, H.; Gao, H.; Wang, J.; Ge, J.; Yao, R.; Ren, C.; Wang, X.B.; et al. Viral effector protein manipulates host hormone signaling to attract insect vectors. Cell Res. 2017, 27, 402-415. [CrossRef]

23. Ninkovic, V.; Feng, Y.; Olsson, U.; Pettersson, J. Ladybird footprints induce aphid avoidance behavior. Biol. Control. 2013, 65, 63-71. [CrossRef]

24. Agarwala, B.K.; Choudhury, P.R. Host races of the cotton aphid, Aphis gossypii, in asexual populations from wild plants of taro and brinjal. J. Insect Sci. 2013, 13, 1-13. [CrossRef]

25. Fereres, A.; Peñaflor, M.F.G.V.; Favaro, C.F.; Azevedo, K.E.X.; Landi, C.H.; Maluta, N.K.P.; Bento, J.M.S.; Lopes, J.R.S. Tomato infection by whitefly-transmitted circulative and non-circulative viruses induce contrasting changes in plant volatiles and vector behaviour. Viruses 2016, 8, 225. [CrossRef]

26. Jahan, S.H.; Lee, G.S.; Lee, S.; Lee, K.Y. Upregulation of probing- and feeding-related behavioural frequencies in Bemisia tabaci upon acquisition of Tomato yellow leaf curl virus. Pest Manag. Sci. 2014, 70, 1497-1502. [CrossRef]

27. Mauck, K.E.; Kenney, J.; Chesnais, Q. Progress and challenges in identifying molecular mechanisms underlying host and vector manipulation by plant viruses. Curr. Opin. Insect Sci. 2019, 33, 7-18. [CrossRef]

28. Fereres, A.; Shukle, R.H.; Araya, J.E.; Foster, J.E. Probing and feeding behavior of Sitobion avenae (F.) (Horn., Aphididae) on three wheat cultivars infected with barley yellow dwarf virus. J. Appl. Entomol. 1990, 109, 29-36. [CrossRef]

29. De Vos, M.; Jander, G. Volatile communication in plant-aphid interactions. Curr. Opin. Plant Biol. 2010, 13, 366-371. [CrossRef]

30. Wu, Y.; Davis, T.S.; Eigenbrode, S.D. Aphid behavioral responses to virus-infected plants are similar despite divergent fitness effects. Entomol. Exp. Appl. 2014, 153, 246-255. [CrossRef]

31. Su, Q.; Preisser, E.L.; Zhou, X.M.; Xie, W.; Liu, B.M.; Wang, S.L.; Wu, Q.J.; Zhang, Y.J. Manipulation of host quality and defense by a plant virus improves performance of whitefly vectors. J. Econ. Entomol. 2015, 108, 11-19. [CrossRef]

32. Dáder, B.; Then, C.; Berthelot, E.; Ducousso, M.; Ng, J.C.K.; Drucker, M. Insect transmission of plant viruses: Multilayered interactions optimize viral propagation. Insect Sci. 2017, 24, 929-946. [CrossRef]

33. Tan, X.L.; Chen, J.L.; Benelli, G.; Desneux, N.; Yang, X.Q.; Liu, T.X.; Ge, F. Pre-infestation of tomato plants by aphids modulates transmission-acquisition relationship among whiteflies, Tomato yellow leaf curl virus (TYLCV) and plants. Front. Plant Sci. 2017, 8, 1597. [CrossRef]

34. Wosula, E.N.; Davis, J.A.; Clark, C.A. Population dynamics of three aphid species (Hemiptera: Aphididae) on four Ipomoea spp. Infected or non-infected with sweetpotato potyviruses. J. Econ. Entomol. 2013, 106, 1566-1573. [CrossRef] 
35. Callaway, R.M.; Thelen, G.C.; Rodriguez, A.; Holben, W.E. Soil biota and exotic plant invasion. Nature 2004, 427, 31-733. [CrossRef]

36. Dunn, A.M.; Torchin, M.E.; Hatcher, M.J.; Kotanen, P.M.; Blumenthal, D.M.; Byers, J.E.; Coon, C.A.C.; Frankel, V.M.; Holt, R.D.; Hufbauer, R.A.; et al. Indirect effects of parasites in invasions. Funct. Ecol. 2012, 26, 1262-1274. [CrossRef]

37. Harding, D.P.; Raizada, M.N. Controlling weeds with fungi, bacteria and viruses: A review. Front. Plant Sci. 2015, 6, 659. [CrossRef]

38. Valles, S.M.; Porter, S.D. Dose response of red imported fire ant colonies to Solenopsis invicta virus 3. Arch. Virol. 2015, 160, 2407-2413. [CrossRef]

39. Arora, A.K.; Douglas, A.E. Hype or opportunity? Using microbial symbionts in novel strategies for insect pest control. J. Insect Physiol. 2017, 103, 10-17. [CrossRef]

40. Valles, S.M.; Hashimoto, Y. Isolation and characterization of Solenopsis invicta virus 3, a new positive-strand RNA virus infecting the red imported fire ant, Solenopsis invicta. Virology 2009, 388, 354-361. [CrossRef]

41. Diaz, R.; Manrique, V.; Hibbard, K.; Fox, A.; Roda, A.; Gandolfo, D.; Medal, J.; Hight, S.; Overholt, W.A. Successful biological control of tropical soda apple (Solanales: Solanaceae) in Florida: A review of key program components. Florida Entomol. 2014, 97, 179-190. [CrossRef]

42. Kollmann, J.; Bañuelos, M.J.; Nielsen, S.L. Effects of virus infection on growth of the invasive alien impatiens glandulifera. Preslia 2007, 79, 33-44.

43. Faillace, C.A.; Lorusso, N.S.; Duffy, S. Overlooking the smallest matter: Viruses impact biological invasions. Ecol. Lett. 2017, 20, 524-538. [CrossRef]

(C) 2019 by the authors. Licensee MDPI, Basel, Switzerland. This article is an open access article distributed under the terms and conditions of the Creative Commons Attribution (CC BY) license (http://creativecommons.org/licenses/by/4.0/). 